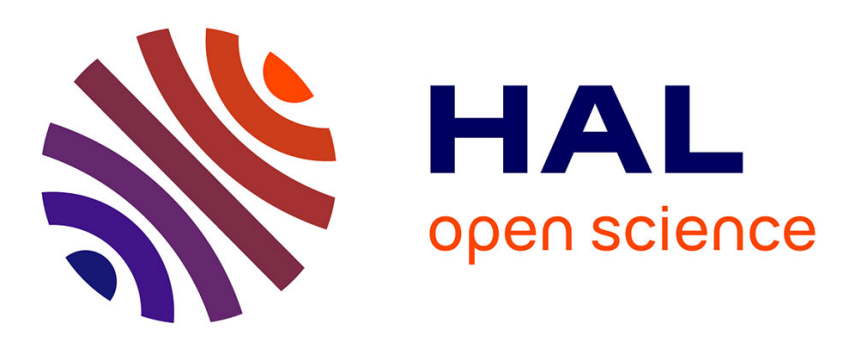

\title{
Kinetic characterization and molecular docking of novel allosteric inhibitors of aminoglycoside phosphotransferases
}

\author{
Nadia Leban, Elise Kaplan, Laurent Chaloin, Sylvain Godreuil, Corinne
} Lionne

\section{To cite this version:}

Nadia Leban, Elise Kaplan, Laurent Chaloin, Sylvain Godreuil, Corinne Lionne. Kinetic characterization and molecular docking of novel allosteric inhibitors of aminoglycoside phosphotransferases. Biochimica et Biophysica Acta (BBA) - General Subjects, 2017, 1861 (1), pp.3464 - 3473. 10.1016/j.bbagen.2016.09.012 . hal-01809565

\section{HAL Id: hal-01809565 \\ https://hal.science/hal-01809565}

Submitted on 30 Nov 2020

HAL is a multi-disciplinary open access archive for the deposit and dissemination of scientific research documents, whether they are published or not. The documents may come from teaching and research institutions in France or abroad, or from public or private research centers.
L'archive ouverte pluridisciplinaire HAL, est destinée au dépôt et à la diffusion de documents scientifiques de niveau recherche, publiés ou non, émanant des établissements d'enseignement et de recherche français ou étrangers, des laboratoires publics ou privés. 


\title{
Kinetic characterization and molecular docking of novel allosteric inhibitors of
} aminoglycoside phosphotransferases

\section{西}

\author{
Nadia Leban ${ }^{\mathrm{a}, 1}$, Elise Kaplan ${ }^{\mathrm{a}, 2}$, Laurent Chaloin ${ }^{\mathrm{a}}$, Sylvain Godreuil ${ }^{\mathrm{b}}$, Corinne Lionne ${ }^{\mathrm{a}, \star, 3}$
} (1)

${ }^{a}$ CNRS FRE 3689 - Université de Montpellier, Centre d'études d'agents Pathogènes et Biotechnologies pour la Santé (CPBS), F-34293 Montpellier, France.

${ }^{\mathrm{b}}$ INSERM U1058 - Université de Montpellier, Centre Hospitalier Régional Universitaire de Montpellier, Département de Bactériologie-Virologie, Montpellier, France.

* Corresponding author at: CBS, 29 rue de Navacelles, F-34090 Montpellier, France; Tel.: +33-(0)626-197-417; Fax : +33-(0)467-417-913.

$$
\text { E-mail address: corinne.lionne@cbs.cnrs.fr }
$$

1 Present address: Institut Supérieur de Biotechnologie de Monastir, Faculty of Pharmacy, University of Monastir, Tunisia.

2 Present address: Department of Pathology, University of Cambridge, Cambridge, United Kingdom.

3 Present address: Centre de Biochimie Structurale, CNRS UMR 5048 - Université de Montpellier - INSERM U 1054, Montpellier, France.

Abbreviations: AME, aminoglycoside-modifying enzyme; AAC, aminoglycoside $N$ acetyltransferase; ANT, aminoglycoside $O$-nucleotidyltransferase; APH, aminoglycoside $O$ phosphotransferase; GOLD, Genetic Optimization for Ligand Docking.

Keywords: allosteric inhibitors, antibiotic resistance, docking, inhibition modes, protein dynamics, steady state kinetics. 
ABSTRACT

Background: Bacterial antibiotic resistance often leads to treatment failure which may have serious consequences, especially in critically sick patients. Resistance to aminoglycosides is mainly due to the expression of antibiotic-modifying enzymes. One important mechanism of aminoglycoside modification is the ATP/GTP-dependent O-phosphorylation catalyzed by aminoglycoside phosphotransferases, APHs. The aim of this study is to identify specific inhibitors of APHs that could restore bacterial susceptibility to aminoglycosides. Methods: We focused on the search for allosteric inhibitors that bind to small cavities of the protein and block the enzyme function by perturbing its dynamics.

Results: From normal mode analysis, a cavity of variable volume belonging to a large groove which splits the protein into two parts was chosen as target. By molecular docking, we screened a large library of commercially available compounds. Seventeen of the highest ranked compounds were tested by in vitro kinetic experiments in order to evaluate their ability to inhibit APHs. Site-directed mutagenesis was carried out with the aim of confirming the inhibition mechanism determined kinetically and the interactions with the protein predicted by in silico studies. These interactions were also confirmed by the use of structurally-related molecules.

Conclusions: Two compounds showed interesting inhibition properties, and one was able to block two different classes of APH.

General significance: This study gives new insights into the inhibition of APHs by such allosteric inhibitors, and provides the basis for the future development of combined therapies, antibiotic plus APH inhibitor, which may reverse the resistance to aminoglycosides in a clinical context. 


\section{Introduction} (5) (4)

of considerable structural diversity. They are broad spectrum antibacterial agents that are products of bacterial or fungal metabolism. Bacterial resistance to aminoglycosides manifests itself by one of the following mechanisms: (i) the presence of aminoglycoside-modifying enzymes [1]; (ii) the decrease of bacteria membrane permeability towards aminoglycoside uptake into the bacteria or extrusion of the aminoglycosides from the cell by efflux pumps [2]; or (iii) the modification of the drug target which can be either mutations that result in structural alterations of the ribosome [3] or methylations by 16S rRNA methyltransferases which interferes with the aminoglycoside binding [4]. Among these mechanisms, inactivation by aminoglycoside-modifying enzymes (AMEs) is the most important both in terms of level and frequency of resistance conferred to the bacteria [5]. There are three types of AMEs, each of which transfers a functional group onto the aminoglycoside structure thereby inactivating the antibiotic: aminoglycoside O-nucleotidyltransferases (ANTs) transfer a nucleoside monophosphate from a nucleoside triphosphate on a hydroxyl group of the antibiotic; aminoglycoside $\mathrm{N}$-acetyltransferases (AACs) transfer an acetyl group from acetylCoA on an amine group; and aminoglycoside O-phosphotransferases (APHs) transfer the $\gamma$ phosphate of a nucleoside triphosphate on a hydroxyl group [6]. Each family of enzymes consists of different isoenzymes that differ in substrate specificity and selectivity. At least 50 different genes for AMEs have been identified in bacteria [1,7]. A number of bacteria also harbor a bifunctional enzyme that catalyzes both acetylation and phosphorylation $[8,9]$. In bacterial resistant isolates that possess antibiotic-inactivating enzymes, drugs are enzymatically modified when they penetrate into the bacteria. Therefore, the altered drug is unable to interact efficiently with its target, the ribosome. Moreover, in the absence of active aminoglycosides that normally perturb bacterial protein synthesis, the next step of high-rate accumulation of antibiotic does not take place $[10,11]$. Since the discovery of the antibioticinactivating enzymes, many efforts have been carried out in order to chemically modify the 
existing antibiotics and produce new drugs that retain their antibacterial activity without being inactivated. This strategy has led to considerable success, especially in the fight against penicillin resistance. For instance, the use of methicillin, a derivative of the early penicillins, overcame enzyme-mediated inactivation in most penicillin-resistant, gram-positive organisms [12]. Another strategy to overcome enzyme-associated resistance consists in combining the antibiotics with an inhibitor of the corresponding modifying enzyme. For example betalactamase inhibitors, such as clavulanic acid, associated with amoxicillin inhibit most strains of penicillinase-producing S. aureus, $H$. influenza, E. coli, Klebsiella spp,... [13]. Based on this strategy, several teams have searched for AMEs inhibitors. The new discovery of AAC inhibition by metal salts (mechanism still unknown) may offer a promising therapeutic issue $[14,15]$. Shi et al. reviewed recent progresses in development of APHs inhibitors [16]. The success in discovering specific inhibitors for AMEs depends on our ability to understand the basic properties of their mode of action and of their substrate specificity. So far, main studies the enzyme with a molecule that binds to a cavity other than the active site, and stabilizes the enzyme in a non-catalytically competent conformation. For example, the inhibition of $\mathrm{APH}\left(3^{\prime}\right)-$ Illa by AR_3a, an ankyrin repeat protein, has been shown to be due to a significant change of the APH conformation upon AR_3a allosteric binding [23]. However, the large size of this modulator makes it hardly druggable.

Here, using normal mode analysis on two different APH crystal structures, we

108 identified a common cavity of variable volume and used it as target for screening a library of 
109 small commercially available compounds. By molecular docking, several potential allosteric

110 inhibitors against two aminoglycoside-modifying enzymes, aminoglycoside 3'111 phosphotransferase type IIIa, APH(3')-IIla, and aminoglycoside 2"-phosphotransferase type 112 IVa, APH(2")-IVa, were identified. We performed kinetic and molecular modelling studies to 113 assess their mechanism of inhibition and to spotlight their binding site in the protein.

114 


\section{Materials and methods}

\subsection{Normal mode analysis and molecular docking}

Two starting crystal structures of APH(3')-IIla (PDB ID: 1L8T, including kanamycin A and ADP, from [24]) and APH(2")-IVa (PDB ID: 3SG8, including tobramycin, from [25]) were

121 selected for normal modes computation and cavity search. In these structures, the 122 aminoglycosides were removed to favour the binding of inhibitors near the target cavity. ADP was maintained in 1L8T, except otherwise stated in the text. The first two hundreds normal modes were calculated (all-atoms parameter set 27) using the VIBRAN module of CHARMM program $[26,27]$ allowing to define fifty conformations for each enzyme. Briefly, after addition of hydrogen using the $\mathrm{H}$-build routine, the potential energy of each system was minimized for

1275,000 steps of conjugate gradient algorithm (tolerance gradient of $0.01 \mathrm{kcal} / \mathrm{mol} / \mathrm{A}$ ) followed 128 by 50,000 steps of Adopted Basis Newton-Raphson to reach a mean energy gradient of less

129 than $10^{-5} \mathrm{kcal} / \mathrm{mol} / \mathrm{A}$. Diagonalization of the Hessian matrix and normal modes were 130 computed from these energy-minimized structures. Trajectories of superimposed modes 131 (modes 7 to 200 , after removal of the six first modes corresponding to intrinsic translational or rotational motions) were computed with CHARMM to produce fifty frames corresponding to

133 protein conformers (hereafter called "trajectory" allowing to visualize the displacement of the

134 whole coordinates on the superposed modes 7 to 200). Atomic fluctuations averaged by 135 residues were computed from normal modes 7-200 using the fluctuation subroutine 136 implemented in the Vibran module of Charmm. Structure and normal modes trajectories were 137 analyzed with VMD software [28]. From these conformers, all cavities were identified and 138 characterized using MDpocket software [29], and a small cavity fulfilling the criteria for 139 allosteric inhibition (location and variable volume) located behind the kanamycin binding site 140 was selected for subsequent screening.

$141 \quad$ All docking was performed using GOLD (Genetic Optimization for Ligand Docking) 142 program v5.2 [30,31]. Zinc database (http://zinc.docking.org) [32] was queried to find drug- 
143 like molecules according to Lipinski's rule-of-five [33]. Briefly, 100,000 compounds from the

144 Zinc database were selected after applying these drug-like filtering criteria, except that logP

145 was defined below or equal to 2 in order to increase the selection of aqueous-soluble 146 compounds. All these molecules were screened by ensemble docking on both APHs using

14720 genetic algorithm runs within a $15 \AA$ radius of the sphere centered on the targeted site

148 and using Goldscore as scoring function. The docking poses were analyzed by the clustering

149 method (complete linkage) from the rmsd matrix of ranking solutions. A second round of

150 molecular docking (50 genetic algorithm runs) was performed on each APH separately, using

151 the highest ranked compounds (the first hundred) from the ensemble screening. Twenty one

152 compounds corresponding to the highest scores were selected, but finally, only seventeen

153 compounds were commercially available and purchased.

154 Structural analysis and visualization of docking poses were carried out using the 155 PyMOL Molecular Graphics System (version 1.3, Schrödinger, LLC).

\subsection{Kinetic studies}

In all in vitro kinetic experiments, equimolar concentrations of $\mathrm{MgCl}_{2}$ were added to

160 ATP. Thus, in the text, ATP and ADP refer to MgATP and MgADP, respectively.

161 Experimental buffer was $50 \mathrm{mM}$ Tris- $\mathrm{HCl} \mathrm{pH} 7.5,1 \mathrm{mM}$ free $\mathrm{MgCl}_{2}, 40 \mathrm{mM} \mathrm{KCl}$, and the

162 temperature was $25^{\circ} \mathrm{C}$. The $\mathrm{APH}$ steady-state activity was evaluated using purified 163 recombinant proteins, produced as previously reported [34], by measuring the time courses 164 of ADP production by two different methods.

For a rapid screening of the compounds, the steady-state rate constants, $k_{\mathrm{ss}}$, of enzyme activity were monitored in 96 -well plates by coupling the release of ADP to a

167 pyruvate kinase/lactate dehydrogenase reaction, as described by McKay et al. [35]. Reaction

168 mixtures contained $0.5 \mu \mathrm{M} \mathrm{APH}, 4 \mathrm{mM}$ phosphoenol pyruvate, $280 \mu \mathrm{M}$ NADH, $20 \mathrm{U} / \mathrm{ml}$ 169 pyruvate kinase, $25 \mathrm{U} / \mathrm{ml}$ lactate dehydrogenase, 25 or $350 \mu \mathrm{M}$ ATP and 50 or $100 \mu \mathrm{M}$ 170 kanamycin A, with $\mathrm{APH}\left(3^{\prime}\right)-$ IIla or $\mathrm{APH}\left(2^{\prime \prime}\right)-\mathrm{IVa}$, respectively. Experiments were carried out in 
171 the absence or in the presence of potential inhibitors at $500 \mu \mathrm{M}$. Reactions were initiated by

172 the addition of ATP and monitored by reading the absorbance at $340 \mathrm{~nm}$ every 11 seconds.

173 Values of $k_{\mathrm{ss}}$ were determined from the slope of linear phase of the reaction time courses

174 using GraFit 7.0.2 software. The experiments were carried out in triplicate and the averaged

175 inhibition was computed.

$176 \quad$ For the best compounds identified by the previously described enzymatic coupled

177 system, the inhibition constants and inhibition modes were determined by the quench-flow

178 method and HPLC analysis as previously described [36]. Briefly, quench-flow method

179 consists in interrupting enzymatic reactions at different times with a quencher, which is

180 usually a strong acid [37]. Here, $10 \%$ perchloric acid was used to stop the reaction every $3-$

$1817 \mathrm{~s}$, depending on the enzyme. The reaction was triggered by addition of ATP in a

182 thermostatically-controlled beaker $\left(25^{\circ} \mathrm{C}\right)$ containing the enzyme and the aminoglycoside,

183 with or without inhibitor. After quenching, the separation of ADP and ATP was carried out

184 using HPLC (Alliance, Waters) and a partisphere SAX column (AIT France). The mobile

185 phase was $200 \mathrm{mM}$ ammonium phosphate buffer $\mathrm{pH} 5.5$ and 10\% acetonitrile. Samples from

186 quench-flow were first spin at $19,000 \mathrm{~g}$ for $20 \mathrm{~min}$ at $4^{\circ} \mathrm{C}$ to remove precipitated protein. A

187 volume of $100 \mu \mathrm{l}$ of supernatant quenched sample was diluted into $900 \mu \mathrm{l}$ of mobile phase

188 supplemented with $\mathrm{KOH}$ to readjust the $\mathrm{pH}$ to 5.5 . Volumes of 50 or $100 \mu \mathrm{l}$ of these samples

189 were injected on the HPLC column. Quantification of ADP and ATP was obtained by

190 integrating absorption peaks at $259 \mathrm{~nm}$ from the chromatograms. The inhibition mode and

191 inhibition constants were determined by repeating the experiment at different concentrations

192 of ATP (keeping kanamycin A concentration constant, see figure legends) or at different

193 concentrations of kanamycin A (ATP concentration constant). APH concentrations were 0.1-

$194 \quad 0.5 \mu \mathrm{M}$. Fittings were performed using GraFit 7.0.2 software using four different inhibition

195 modes: competitive, non-competitive, uncompetitive and mixed. Only the most appropriate fit

196 (which describes the inhibition with the lowest $\mathrm{Chi}^{2}$ ) is shown on the figures with the

197 corresponding Lineweaver-Burk representation.

198 
R211A mutant of $\mathrm{APH}\left(3^{\prime}\right)$-IIla was constructed by PCR (QuickChange Lightning Multi

202 Site-Directed Mutagenesis Kit) using the two primers :

203 5'-TTTATTGATCTTGGGGCAAGCGGCAGGGCGGAC-3,' and

204 5'-GTCCGCCCTGCCGCTTGCCCCAAGATCAATAAA-3'.

205 Each $50 \mu \mathrm{l} \mathrm{PCR}$ reaction contained $2.5 \mu \mathrm{l}$ of $10 \times$ QuickChange Lightning Multi 206 reaction buffer, $0.75 \mu$ of QuickSolution, $100 \mathrm{ng}$ of DNA template (wild type aph(3')-IIla in a 207 pET15b plasmid), $1 \mu$ of each mutagenic primer (100 ng), $10 \mathrm{mM}$ dNTP and 2.5 units of 208 QuickChange Lightning Multi enzyme blend. The PCR product was digested by Dpnl 209 restriction endonuclease for $1 \mathrm{~h}$ at $37^{\circ} \mathrm{C}$. Mutant plasmids were recovered after 210 transformation in E. coli BL21 (DE3) chemo-competent cells. Successful introduction of the 211 desired mutations was controlled by sequencing the plasmid DNA (Fig. S1).

212 The mutant $\mathrm{APH}\left(3^{\prime}\right)$-IIla was produced in E. coli and purified as the wild type protein. 


\section{Results}

\subsection{Target cavity identification by normal mode analysis}

Here, we focused on the search for APH allosteric inhibitors that bind to small cavities of the protein and block the enzyme function by perturbing its dynamics. Thus, a specific cavity was defined according to the following criteria: the cavity must be present in different APH subfamilies, it must be outside of the substrate binding sites, and lastly, it must undergo obvious volume change during the dynamics of the enzyme, required for its function. Subfamilies $\mathrm{APH}\left(3^{\prime}\right)$ and $\mathrm{APH}(2 ")$ were chosen because of their prevalence [1].

From the normal mode analysis, one cavity behind the aminoglycoside binding site was selected because it was fulfilling all the predefined criteria (Fig. 1, Fig. S2 also showing videos). It belongs to a large groove which splits the proteins into two parts. Moreover, the

227 region defining this cavity was found to be flexible according to the fluctuations computed 228 from the superposed normal modes (Fig. 1). It must be emphasized that the observed atomic 229 fluctuations were relatively small and therefore were not considered as the main criteria to 230 select the cavity (commonly, fluctuations of residues located at the interior of the protein are 231 less important compared to external flexible loops). Typically, APH proteins do not require 232 large collective motions like other kinases for their biological function and this feature renders 233 more difficult the search for internal dynamic cavities. Nevertheless and taking into account 234 to these small fluctuations, the target binding pocket was also selected in respect to the 235 volume changes observed along the normal modes. The target cavities were surrounded by 236 residues Gly192 and Arg226 in 1L8T structure and by residues Ser199 and Ser232 in 3SG8 237 (yellow balls in Fig. S2). They are situated at a similar place within the two APHs and their 238 compositions in amino acids were similar but not identical (at least one Phe, Leu, Ile, Ser and 239 Asp found in each case).

\section{Figure 1}




\subsection{Molecular docking}

Using the targeted cavity defined above in $\mathrm{APH}\left(3^{\prime}\right)-\mathrm{IIla}$ and $\mathrm{APH}\left(2^{\prime \prime}\right)-\mathrm{IVa}$ structures and the ZINC chemicals database [32], a virtual screening was carried out in order to predict 246 and evaluate the potential affinity of these enzymes for drug-like molecules using Gold 247 software. The Goldscore scoring function was used to rank the screened molecules - the 248 highest scores predict highest affinities. In order to favor the binding of inhibitors near the 249 target cavity which is located behind the aminoglycoside binding site, kanamycin A was removed from 1L8T structure (but not ADP) and tobramycin from 3SG8 prior docking.

In a first case study using an ensemble docking after overlaying both APH (same center of coordinates defining the target cavity at the same location for the two APHs), the first 100 out of the 100,000 compounds from the drug-like ZINC subset were selected based on their docking scores. Then, a second thorough docking run (50 GA runs) was performed on each APH separately with these selected compounds. We finally selected 21 best ranking ligands $(63<$ score $<81)$ after named NL1 to NL21 (Table 1). NL4, NL7, NL10 and NL15 were not commercially available, and therefore only $17 \mathrm{NL}$ compounds were purchased for the further experimental assays.

3.3. Rapid in vitro screening of APH inhibitors using a coupled enzyme kinetic assay.

To evaluate the potential APH inhibition promoted by the selected molecules, in vitro inhibition studies were performed. The 17 molecules were rapidly screened using an enzymatic coupled-system, as previously described [35]. We used kanamycin A for these studies because both APHs can phosphorylate this aminoglycoside with a good efficiency 266 through a Michaelis-Menten kinetics. Steady-state rate constants $\left(k_{\mathrm{ss}}\right)$ were measured at 267 fixed concentrations of ATP and kanamycin A, in the absence or in the presence of NL 268 compounds $(500 \mu \mathrm{M})$. Percentages of inhibition by $\mathrm{NL}$ compounds were determined and normalized in respect to the activity without compound. The results are summarized in Table 
270 1. In these conditions, a $40 \%$ or higher inhibition of $\mathrm{APH}\left(3^{\prime}\right)$-IIla activity was observed with 271 compounds NL6 and NL8, and for APH(2")-IVa with compounds NL6, NL9 and NL16. Two 272 compounds seemed particularly interesting: NL8 because it inhibits APH(3')-IIla by almost $27380 \%$, and NL6 for its ability to inhibit both APHs.

In order to determine the inhibition mode of these two compounds, steady-state kinetic experiments were carried out using a direct quenched-flow method. Results are described below and their mechanism is discussed on the basis of docking experiments.

3.3.1. Inhibition by NL8 compound.

NL8 was the most potent inhibitor amongst the 17 molecules tested here by the coupled system, showing a $79 \%$ inhibition of $\mathrm{APH}\left(3^{\prime}\right)-$ IIla activity at $500 \mu \mathrm{M}$. However, it showed little inhibition of $\mathrm{APH}(2 ")-\mathrm{IVa}$ activity. The steady-state rate constants, $k_{\mathrm{ss}}$, of $\mathrm{APH}\left(3^{\prime}\right)$-IIla were determined at different concentrations of kanamycin A or ATP, and at 0,50 or $100 \mu \mathrm{M}$ concentrations of NL8 by the quenched-flow method. Double reciprocal plots of $1 / k_{\mathrm{ss}}$ versus $1 /[\mathrm{ATP}]$ or $1 /[$ kanamycin A] are shown in Fig. 2.

The NL8 compound was found to be a competitive inhibitor of $\mathrm{APH}\left(3^{\prime}\right)$-IIla towards ATP with a $K_{\mathrm{i}}$ of $9 \pm 2 \mu \mathrm{M}$, and a non-competitive inhibitor towards kanamycin A with a $K_{\mathrm{i}}$ of $55 \pm 2 \mu \mathrm{M}$

It should be noted that NL8 was initially identified as potential allosteric inhibitor on the basis of a docking on $\mathrm{APH}\left(3^{\prime}\right)$-IIla.ADP complex. To explain the unexpected ATP competitive inhibition mode found here, we carried out another docking of NL8 but in the absence of ADP (Fig. S3). In these conditions, NL8 was found to overlap with the nucleotide binding site, especially with the phosphate groups of the nucleotide. Unfortunately, it was difficult to predict with accuracy the binding of NL8 as the molecule presents a high degree of variability, even within repetitions of dockings (several rounds using identical parameters). 
Similar variabilities were obtained when NL8 was docked in the apo, in the kanamycin-bound or in the ADP-bound structures.

NL8 was identified on the basis of an in silico screening in which the cavity of the targeted protein was located behind the aminoglycoside binding pocket (Fig. 1). However, the competition between ATP and NL8 upon binding to APH(3')-IIla suggests than the inhibitor may bind to a different location, presumably closer to the nucleotide binding pocket without interfering with the aminoglycoside site.

\subsubsection{Inhibition by NL6 compound.}

The coupled enzyme system method showed that NL6 inhibited efficiently both enzymes with $43 \%$ and $63 \%$ inhibition for $\mathrm{APH}\left(3^{\prime}\right)-\mathrm{IIla}$ and $\mathrm{APH}\left(2^{\prime \prime}\right)-\mathrm{IVa}$, respectively.

We determined the mode of inhibition of each protein by NL6. Fig. 3A and B show that NL6 is a non-competitive inhibitor of APH(2")-IVa towards both ATP and kanamycin A with $K_{\mathrm{i}}$ of $85 \pm 10 \mu \mathrm{M}$ and $74 \pm 4 \mu \mathrm{M}$, respectively. Similarly, kinetics with $\mathrm{APH}\left(3^{\prime}\right)$-IIla showed

312 NL6 acts again as a non-competitive inhibitor towards ATP and kanamycin A with $K_{\mathrm{i}}$ of $31375 \pm 3 \mu \mathrm{M}$ and $76 \pm 6 \mu \mathrm{M}$, respectively (Fig. 3C and D).

To further investigate the binding of NL6 to APH(3')-IIla, molecular docking of NL6 316 was performed in the apo protein, in the ADP-bound structure and in the ternary complex 317 (PDB ID: 1L8T). Although NL6 is acting on both APHs' activity, it was more difficult to predict 318 the binding position of NL6 in $\mathrm{APH}\left(2^{\prime \prime}\right)-I V a$. Therefore, we focused on APH(3')-IIla here. A 319 cluster of the best docking poses is shown in Fig. 4A, B, C for each simulation. Interestingly, 320 if one part of the molecule presents an important degree of flexibility in the apo and in the 321 ADP-bound structures, the dihydro-benzopyran ring of NL6 shows a rigorously identical 322 location in all docking predictions, suggesting the importance of this group for NL6 binding. 323 The interactions occurring between this moiety and the protein are detailed in Fig. 4D. 
All molecular dockings predicted that the dihydro-benzopyran ring is stabilized by the backbone atoms of Leu209 and Gly210 and by a hydrogen bond between the carbonyl near the benzopyran ring and the side chain of Arg211 (Fig. 4D). This latter interaction seems to be of a crucial importance to stabilize the molecule as NL6 presents a completely different predicted location when Arg211 is replaced by an alanine (Fig. 4E). To assess the importance of this interaction for the in vitro binding of NL6, we engineered the R211A mutant of $\mathrm{APH}\left(3^{\prime}\right)$-IIla and performed kinetic studies in the absence or in the presence of NL6. The activity of this mutant was significantly affected: $k_{\text {cat }}$ was decreased by $62 \%$. Interestingly, the molecule was completely unable to inhibit the APH mutant (Fig. 4F). This result confirms the binding site of NL6 predicted by in silico studies and highlights the importance of Arg211 for its binding to APH.

To further investigate the importance of the two other interactions occurring with the benzopyran ring, we tested the activity of structurally related compounds. Indeed, the benzopyran moiety is stabilized by two hydrogen bonds with the backbones of Leu209 and Gly210, it was thus impossible to modify these interactions by mutations. Consequently, we evaluated the activity of two structurally related molecules. One of them, named NL6-1 (Zinc14108604), contains the same dihydro-benzopyran ring than NL6 but with a slightly shorter structure, while the other compound, NL6-2 (Zinc13235262), has a naphthyl group instead. According to ZINC chemical database, the two analogues show more than $70 \%$ of structural similarity with NL6 (Fig. 5A).

Dockings were achieved in the APH(3')-IIla with NL6 and its two analogues using the same parameters. According to these in silico studies, the two molecules bind to the same position to that observed for NL6 in the substrate-bound structure of $\mathrm{APH}\left(3^{\prime}\right)$-IIla (Fig. $5 \mathrm{C}$ and D). However, the naphthyl group of NL6-2 does not interact with the protein in contrast to the dihydro-benzopyran group NL6-1 which has similar interactions to those of NL6. Similarly, when docked in the apo protein, NL6 and NL6-1 show a strict overlay of their dihydrobenzopyran group, while NL6-2 presents a completely different binding mode (Fig. 5E and F). The naphthyl group of NL6-2 is indeed located at the opposite side from ADP in contrast 
353 to the dihydro-benzopyran moiety of NL6 and NL6-1, located near the nucleotide binding site.

354 This suggests that the benzopyran ring is also important for the stabilization of NL6.

Figure 5

Based on this prediction, these molecules were tested in vitro to estimate their ability to inhibit the $\mathrm{APH}\left(3^{\prime}\right)-$ IIla activity. As shown in Fig. 5B, NL6-1 inhibits the activity of the APH.

358 Similarly to NL6, NL6-1 was confirmed to act as a non-competitive inhibitor towards ATP with $359 \quad$ a $K_{\mathrm{i}}$ of $185 \pm 12 \mu \mathrm{M}$ (data not shown). The 2 -fold higher $K_{\mathrm{i}}$ of NL6-1 compared to NL6 can be 360 explained by its shorter structure ( 20 carbons) compared to NL6 (23 carbons), resulting in a 361 smaller number of interactions with the protein and consequently in a weaker inhibition. In 362 contrast, NL6-2 was completely unable to inhibit the APH activity, confirming the hypothesis that the dihydro-benzopyran group is of major importance for APH inhibition.

According to kinetic and molecular docking studies, NL6 is likely to bind between both substrates, without affecting their binding. The presence of NL6 should greatly perturb the 366 phosphotransfer of the $\mathrm{y}$-phosphate of ATP on the 3'-OH of kanamycin A which could explain 367 the enzyme inhibition.

To conclude, the dihydro-benzopyran ring is of crucial importance for the binding of 369 NL6 to APH enzymes. In addition, the two interactions with side chain of Arg211 and backbones of Leu209 and Gly210 were shown to play an essential role in the inhibition of 371 APH. 


\section{Discussion}

The problem of bacterial resistance to antibiotic due to aminoglycoside phosphotransferases $\mathrm{APH}\left(2^{\prime \prime}\right)-\mathrm{IVa}$ and $\mathrm{APH}\left(3^{\prime}\right)$-IIla enzymes could be overcome by the development of novel drugs that target APHs, as suggested by Shi and co-authors in a

379 recent review [16]. For example, because of the structural similarity of the ATP binding

380 domain with protein kinases, APHs can be inhibited by eukaryotic protein kinase inhibitors. In

381 this way, protein kinase inhibitors of the isoquinoline sulfonamide family have been shown to 382 be competitive inhibitors of $\mathrm{APH}\left(3^{\prime}\right)$-IIla towards ATP, although they were unable to restore 383 aminoglycoside susceptibility of strains harboring aph(3')-IIla gene [38]. In the same manner, 384 Shakya et al. screened a library of known kinase inhibitors and identified pyrido-pyrimidines 385 as selective inhibitors of $\mathrm{APH}\left(3^{\prime}\right)$ s and flavonoids as general inhibitors of APHs [39]. A crystal 386 structure of the $\mathrm{APH}(2 ")-I V a \cdot k a n a m y c i n \cdot q u e r c e t i n$ complex allowed to confirm that the 387 inhibitor binds to the ATP binding site of the enzyme.

The problem with such kinase inhibitors is their intrinsic poor selectivity because they target the ATP binding site of APHs which is similar to that of many eukaryotic important enzymes. However, the recent structure-guided optimization of protein kinase inhibitors constitutes a promising strategy to enhance their specificity for APHs [18]. The originality of our inhibitors, compared to these protein kinase inhibitors, is that they do not target the substrate binding site, hence avoiding or reducing off-target effects. Therefore, they are

394 neither going to compete with the antibiotic itself for the binding to APHs or to the rRNA 395 target, nor with ATP which has a central role in many physiological processes. Instead, they 396 have been selected for their ability to interfere with important dynamic properties of the 397 targeted enzyme.

A similar strategy was successful applied to APH with the development of allosteric inhibitors based on engineered ankyrin repeat motives. These compounds inhibited the 400 enzyme activity, both in vitro and in vivo, and were able to restore the bacteria sensitivity to 401 kanamycin and amikacin to a level comparable to that of the corresponding knockout strains 
402 [40]. Later, the resolution of the crystal structure of $\mathrm{APH}\left(3^{\prime}\right)-$-IIla complexed with one of the 403 most potent ankyrin repeat protein inhibitor has confirmed the allosteric inhibition mechanism 404 [23]. Indeed, the binding of the inhibitor stabilizes the APH in a non-catalytically competent conformation. However, the designed ankyrin repeat protein is a large molecule that is hardly 406 druggable.

Here, on the basis of in silico screening of a chemical library, our idea was to find 408 small molecules that are more druggable than large proteins and that inhibit APHs in a 409 similar manner to that of ankyrin repeat protein. Allosteric small-molecule kinase inhibitors are indeed promising alternatives to active site binders, as recently reviewed [41].

We have identified twenty one small molecules that are potential allosteric inhibitors 412 of APHs. Out of the seventeen that were evaluated, four molecules were able to inhibit 413 significantly APH activity in vitro. We determined the mode of inhibition for two of them and 414 showed that they are non-competitive towards kanamycin A. One of them, NL8, was a 415 competitive inhibitor of $\mathrm{APH}\left(3^{\prime}\right)$-IIla towards ATP, suggesting that it should bind near the 416 nucleotide binding position, but its precise binding position remains elusive. The fact that it 417 did not inhibit APH(2")-IVa suggests that it does not bind to the nucleotide binding site which 418 is conserved between the two APHs. The most promising molecule, NL6, is able to inhibit non-competitively the two APHs tested. Its binding site was confirmed both by mutating one 420 interacting residue of APH and by the use of NL6 analogues with one missing the dihydro421 benzopyran ring required for an efficient binding. As shown in Fig. 6, NL6 binds to a different 422 location in $\mathrm{APH}\left(3^{\prime}\right)$-IIla that of the protein kinase inhibitor $\mathrm{CKI}$, and of the ankyrin-repeat 423 protein inhibitor AR-3A.

\section{Figure 6}

This confirms that non-allosterically modulated proteins such as APHs can be inhibited by small druggable allosteric compounds, which brings new insights for the rational drug discovery of APHs inhibitors.

The seventeen compounds will be further tested for their effect on antibiotic 
430 their potential cell toxicity. The integration of dynamic motions by using normal mode 431 analysis in combination with molecular docking, enzyme kinetics and antibacterial activity 432 studies, provided important insights into the molecular basis underlying ligand binding and 433 enzyme inhibition. Co-crystallization assays of APHs with these molecules are currently in 434 progress and rational lead optimization processes are considered in order to design new 435 derivatives with higher inhibitory properties. Efforts should be made to increase the affinity of $436 \mathrm{APH}$ for the inhibitor by adding chemical substitutions that would interact with additional 437 residues of the cavity. This should avoid that a single mutation of the protein is enough to 438 prevent the inhibition. 


\section{Conclusion}

441

442 Optimization of the lead compounds identified in this study should help in the design

443 of efficient APHs inhibitors that may overcome APH-dependent bacterial resistance to 444 aminoglycosides. Emergence and frequency of potential resistance mutants will be evaluated 445 in vitro. Moreover, this strategy may be applied to other multi-resistant strains for which the 446 major AMEs have been identified.

447

448 


\section{Acknowledgment}

450

451 This work was supported by the Centre National de la Recherche Scientifique 452 (CNRS), the University of Montpellier and the Agence Nationale de la Recherche (ANR 453 Programme Blanc 2011-SIMI7, "cN-II Focus"). France-Tunisia exchange was supported by a 454 CNRS program (EDC25987). Dr. Nadia Leban is grateful to the Infectiopôle Sud Foundation 455 for a post-doctoral fellowship and Dr. Elise Kaplan to the Fondation pour la Recherche 456 Médicale for doctoral fellowship (FDT20140931113).

457 We thank Professor Sergei B. Vakulenko (Notre Dame, USA) and Professor Engin H. 458 Serpersu (Knoxville, USA) for the generous gift of the aph(2")-IVa and aph(3')-IIla genes. We 459 thank Ms Perrine Lallemand (CPBS) for her help in the APH purification procedure.

460 461 


\section{References}

463

464 [1] Ramirez MS \& Tolmasky ME (2010) Aminoglycoside modifying enzymes. Drug Resist. Updat. 13, 151-171.

466 [2] Kumar A \& Schweizer HP (2005) Bacterial resistance to antibiotics: active efflux and reduced uptake. Adv. Drug Deliv. Rev. 57, 1486-1513.

[3] Pfister P, Hobbie S, Vicens Q, Böttger EC \& Westhof E (2003) The molecular basis for A-site mutations conferring aminoglycoside resistance: relationship between ribosomal

[4] Doi Y \& Arakawa Y (2007) 16S ribosomal RNA methylation: emerging resistance mechanism against aminoglycosides. Clin. Infect. Dis. 45, 88-94.

[5] Vakulenko SB \& Mobashery S (2003) Versatility of aminoglycosides and prospects for their future. Clin. Microbiol. Rev. 16, 430-450.

[6] Wright GD, Berghuis AM \& Mobashery S (1998) Aminoglycoside antibiotics. Structures, functions, and resistance. Adv. Exp. Med. Biol. 456, 27-69.

[7] Shaw KJ, Rather PN, Hare RS \& Miller GH (1993) Molecular genetics of aminoglycoside resistance genes and familial relationships of the aminoglycosidemodifying enzymes. Microbiol. Rev. 57, 138-163.

[8] Ferretti JJ, Gilmore KS \& Courvalin P (1986) Nucleotide sequence analysis of the gene specifying the bifunctional 6'-aminoglycoside acetyltransferase 2"-aminoglycoside phosphotransferase enzyme in Streptococcus faecalis and identification and cloning of gene regions specifying the two activities. J. Bacteriol. 167, 631-638.

[9] Azucena E, Grapsas I \& Mobashery S (1997) Properties of a bifunctional bacterial antibiotic resistance enzyme that catalyzes ATP-dependent 2"-phosphorylation and acetyl-CoA-dependent 6'-acetylation of aminoglycosides. J. Am. Chem. Soc. 119, 2317-2318.

[10] Dickie P, Bryan LE \& Pickard MA (1978) Effect of enzymatic adenylylation on dihydrostreptomycin accumulation in Escherichia coli carrying an R-factor: model 
explaining aminoglycoside resistance by inactivating mechanisms. Antimicrob. Agents Chemother. 14, 569-580.

492 [11] Höltje JV (1979) Induction of streptomycin uptake in resistant strains of Escherichia coli. Antimicrob. Agents Chemother. 15, 177-181.

494 [12] Bush K \& Mobashery S (1998) How beta-lactamases have driven pharmaceutical drug discovery. From mechanistic knowledge to clinical circumvention. Adv. Exp. Med. Biol. 456, 71-98.

[13] Drawz SM \& Bonomo RA (2010) Three decades of beta-lactamase inhibitors. Clin. Microbiol. Rev. 23, 160-201.

[14] Chiem K, Fuentes BA, Lin DL, Tran T, Jackson A, Ramirez MS \& Tolmasky ME (2015) Inhibition of aminoglycoside 6'-N-acetyltransferase type lb-mediated amikacin resistance in Klebsiella pneumoniae by zinc and copper pyrithione. Antimicrob. Agents Chemother. 59, 5851-5853.

[15] Li Y, Green KD, Johnson BR \& Garneau-Tsodikova S (2015) Inhibition of 504 aminoglycoside acetyltransferase resistance enzymes by metal salts. Antimicrob.

[16] Shi K, Caldwell SJ, Fong DH \& Berghuis AM (2013) Prospects for circumventing aminoglycoside kinase mediated antibiotic resistance. Front. Cell. Infect. Microbiol. 3, 22.

[17] Fong DH, Xiong B, Hwang J \& Berghuis AM (2011) Crystal structures of two aminoglycoside kinases bound with a eukaryotic protein kinase inhibitor. PloS One 6,

512 [18] Stogios PJ, Spanogiannopoulos P, Evdokimova E, Egorova O, Shakya T, Todorovic N, Capretta A, Wright GD \& Savchenko A (2013) Structure-guided optimization of protein kinase inhibitors reverses aminoglycoside antibiotic resistance. Biochem. J. 454, 191200. 
[19] Szychowski J, Kondo J, Zahr O, Auclair K, Westhof E, Hanessian S \& Keillor JW (2011) Inhibition of aminoglycoside-deactivating enzymes $\mathrm{APH}\left(3^{\prime}\right)-\mathrm{IIla}$ and $\mathrm{AAC}\left(6^{\prime}\right)-\mathrm{li}$ by amphiphilic paromomycin O2"-ether analogues. ChemMedChem 6, 1961-1966.

[20] Vong K, Tam IS, Yan X \& Auclair K (2012) Inhibitors of aminoglycoside resistance activated in cells. ACS Chem. Biol. 7, 470-475.

[21] Welch KT, Virga KG, Whittemore NA, Özen C, Wright E, Brown CL, Lee RE \& Serpersu EH (2005) Discovery of non-carbohydrate inhibitors of aminoglycosidemodifying enzymes. Bioorg. Med. Chem. 13, 6252-6263.

[22] Lin DL, Tran T, Adams C, Alam JY, Herron SR \& Tolmasky ME (2013) Inhibitors of the aminoglycoside $6^{\prime}-N$-acetyltransferase type $\mathrm{lb}\left[\mathrm{AAC}\left(6^{\prime}\right)-\mathrm{lb}\right]$ identified by in silico

[23] Kohl A, Amstutz P, Parizek P, Binz HK, Briand C, Capitani G, Forrer P, Plückthun A \&

[25] Shi K, Houston DR \& Berghuis AM (2011) Crystal structures of antibiotic-bound complexes of aminoglycoside 2"-phosphotransferase IVa highlight the diversity in substrate binding modes among aminoglycoside kinases. Biochemistry 50, 6237-6244.

[26] Brooks BR, Brooks CL, Mackerell AD, Nilsson L, Petrella RJ, Roux B, Won Y, Archontis G, Bartels C, Boresch S, Caflisch A, Caves L, Cui Q, Dinner AR, Feig M, Fischer S, Gao J, Hodoscek M, Im W, Kuczera K, Lazaridis T, Ma J, Ovchinnikov V, Paci E, Pastor RW, Post CB, Pu JZ, Schaefer M, Tidor B, Venable RM, Woodcock HL, Wu X, Yang W, York DM \& Karplus M (2009) CHARMM: the biomolecular simulation program. J. Comput. Chem. 30, 1545-1614.

[27] Zhu X, Lopes PEM \& Mackerell AD (2012) Recent Developments and Applications of the CHARMM force fields. Wiley Interdiscip. Rev. Comput. Mol. Sci. 2, 167-185. 
543 [28] Humphrey W, Dalke A \& Schulten K (1996) VMD: visual molecular dynamics. J. Mol. $544 \quad$ Graph. 14, 33-38, 27-28.

545 [29] Schmidtke P, Bidon-Chanal A, Luque FJ \& Barril X (2011) MDpocket: open-source cavity detection and characterization on molecular dynamics trajectories. Bioinformatics 27, 3276-3285.

[30] Jones G, Willett P \& Glen RC (1995) Molecular recognition of receptor sites using a genetic algorithm with a description of desolvation. J. Mol. Biol. 245, 43-53.

[31] Jones G, Willett P, Glen RC, Leach AR \& Taylor R (1997) Development and validation of a genetic algorithm for flexible docking. J. Mol. Biol. 267, 727-748.

[32] Irwin JJ, Sterling T, Mysinger MM, Bolstad ES \& Coleman RG (2012) ZINC: a free tool to discover chemistry for biology. J. Chem. Inf. Model. 52, 1757-1768.

[33] Lipinski CA (2004) Lead- and drug-like compounds: the rule-of-five revolution. Drug Discov. Today Technol. 1, 337-341.

[34] Lallemand P, Leban N, Kunzelmann S, Chaloin L, Serpersu EH, Webb MR, Barman T \& Lionne C (2012) Transient kinetics of aminoglycoside phosphotransferase(3')-IIla reveals a potential drug target in the antibiotic resistance mechanism. FEBS Lett. 586, 4223-4227.

[35] McKay GA, Thompson PR \& Wright GD (1994) Broad spectrum aminoglycoside phosphotransferase type III from Enterococcus: overexpression, purification, and substrate specificity. Biochemistry 33, 6936-6944.

[36] Kaplan E, Guichou J-F, Chaloin L, Kunzelmann S, Leban N, Serpersu EH \& Lionne C (2016) Aminoglycoside binding and catalysis specificity of aminoglycoside 2"phosphotransferase IVa: A thermodynamic, structural and kinetic study. Biochim. Biophys. Acta 1860, 802-813.

567 [37] Barman TE, Bellamy SRW, Gutfreund H, Halford SE \& Lionne C (2006) The 568 identification of chemical intermediates in enzyme catalysis by the rapid quench-flow 569 technique. Cell. Mol. Life Sci. 63, 2571-2583. 
570 [38] Daigle DM, McKay GA \& Wright GD (1997) Inhibition of aminoglycoside antibiotic 571 resistance enzymes by protein kinase inhibitors. J. Biol. Chem. 272, 24755-24758.

572 [39] Shakya T, Stogios PJ, Waglechner N, Evdokimova E, Ejim L, Blanchard JE, McArthur 573 AG, Savchenko A \& Wright GD (2011) A small molecule discrimination map of the antibiotic resistance kinome. Chem. Biol. 18, 1591-1601.

575 [40] Amstutz P, Binz HK, Parizek P, Stumpp MT, Kohl A, Grütter MG, Forrer P \& Plückthun A (2005) Intracellular kinase inhibitors selected from combinatorial libraries of designed ankyrin repeat proteins. J. Biol. Chem. 280, 24715-24722.

578 [41] Wu P, Clausen MH \& Nielsen TE (2015) Allosteric small-molecule kinase inhibitors. Pharmacol. Ther. 156, 59-68. 
Fig. 1. Identification of the target cavities using normal mode analysis. (A) Crystal structure of $\mathrm{APH}\left(3^{\prime}\right)$-IIla shown as blue cartoon, complexed with $\mathrm{ADP}$ and kanamycin $\mathrm{A}$ in stick representation (PDB ID: 1L8T). (B) Detection of all the dynamic cavities, shown in mesh representation, from the fifty frames of the trajectory of the 200 first normal modes of $1 \mathrm{~L} 8 \mathrm{~T}$ structure depleted of ligands. (C)

(C) Selected cavil avity used for virtual screening. (D) Crystal structure of $\mathrm{APH}(2 ")-\mathrm{IVa}$ shown as pink cartoon, complexed with tobramycin in stick representation (PDB ID: 3SG8). (E) Detection of dynamic cavities of 3SG8 structure without tobramycin. (F) Selected cavity used for virtual screening. (G) Volume of the target cavities (shown in $\mathrm{C}$ and $\mathrm{F}$ ) showing variation along the normal modes trajectory of $\mathrm{APH}\left(3^{\prime}\right)$-IIla (in 592 blue) and $\mathrm{APH}(2 ")$-IVa (in red). ( $\mathrm{H}$ and I) Atomic fluctuations averaged by residue computed 593 from normal mode analysis for $\mathrm{APH}\left(3^{\prime}\right)-\mathrm{IIla}$ (1L8T) and $\mathrm{APH}(2 ")-\mathrm{IVa}$, respectively. The 594 numbers highlight residues showing significant fluctuations (for more details, see Fig. S2).

Fig. 2. Determination of $A P H\left(3^{\prime}\right)$-IIla inhibition mode by NL8. (A) Competitive inhibition profile by NL8 towards ATP. Final concentrations were $0.1 \mu \mathrm{M}$ APH(3')-IIla, $50 \mu \mathrm{M}$ kanamycin $\mathrm{A}$ and 5-500 $\mu \mathrm{M}$ ATP. (B) Non-competitive inhibition profile by NL8 towards kanamycin A. Final 599 concentrations were $0.1 \mu \mathrm{M} \mathrm{APH}\left(3^{\prime}\right)$-IIla, 5-200 $\mu \mathrm{M}$ kanamycin A and $25 \mu \mathrm{M}$ ATP. 600 Lineweaver-Burk representations are shown but the fits were carried out on raw data. NL8 601 concentrations were $0 \mu \mathrm{M}$ (circles), $50 \mu \mathrm{M}$ (squares) or $100 \mu \mathrm{M}$ (triangles).

602

603 Fig. 3. Determination of the inhibition mode of $\mathrm{APH}\left(2^{\prime \prime}\right)-\mathrm{IVa}(\mathrm{A}, \mathrm{B})$ or $\mathrm{APH}\left(3^{\prime}\right)-\mathrm{III}(\mathrm{C}, \mathrm{D})$ by 604 NL6. Final concentrations were (A) $0.5 \mu \mathrm{M}$ APH(2")-IVa, $100 \mu \mathrm{M}$ kanamycin A and 50-500 $605 \mu \mathrm{M}$ ATP; (B) $0.5 \mu \mathrm{M}$ APH(2")-IVa, 5-150 $\mu \mathrm{M}$ kanamycin A and $400 \mu \mathrm{M}$ ATP; (C) $0.1 \mu \mathrm{M}$ $606 \mathrm{APH}\left(3^{\prime}\right)$-IIla, $50 \mu \mathrm{M}$ kanamycin A and 5-250 $\mu \mathrm{M}$ ATP; (D) $0.1 \mu \mathrm{M}$ APH(3')-IIIa, 5-100 $\mu \mathrm{M}$ 607 kanamycin A and $25 \mu \mathrm{M}$ ATP. NL6 concentrations were $0 \mu \mathrm{M}$ (circles), $20 \mu \mathrm{M}$ (triangles) or $60850 \mu \mathrm{M}$ (squares). 
610 Fig. 4. (A, B, C) Clusters of docking poses of NL6 in the apo, in the ADP-bound and in the 611 ternary structures of $\mathrm{APH}\left(3^{\prime}\right)$-IIla, respectively. The stable dihydro-benzopyran group of NL6 612 is shown surrounded by a dashed line. (D) Details of interactions of the dihydro-benzopyran 613 ring of NL6 with APH(3')-IIla. (E) Docking of NL6 in the substrate-bound structure of APH(3')614 Illa R211A mutant. (F) Steady state activity of $\mathrm{APH}\left(3^{\prime}\right)$-IIla R211A mutant as a function of 615 ATP concentration in the absence (circles) or in the presence of NL6 (squares). Final 616 concentrations were $0.2 \mu \mathrm{M}$ R211A APH(3')-IIla, $50 \mu \mathrm{M}$ kanamycin A, 5-100 $\mu \mathrm{M}$ ATP, and 0 617 or $50 \mu \mathrm{M}$ NL6.

618

619 Fig. 5. (A) Structure of NL6 and the two selected analogues, NL6-1 and NL6-2. (B) 620 Comparison of $\mathrm{APH}\left(3^{\prime}\right)$-IIla steady state activity as a function of ATP concentration in the 621 absence of NL compound (circles) or in the presence of NL6 (squares), NL6-1 (triangles) or 622 NL6-2 (stars). Final concentrations were $0.1 \mu \mathrm{M}$ APH(3')-IIla, $50 \mu \mathrm{M}$ kanamycin A, 5-100 $\mu \mathrm{M}$ 623 ATP, and 0 or $50 \mu \mathrm{M} \mathrm{NL}$ compounds. (C, D) Overlay of the best docking poses of NL6 (grey) 624 and NL6-1 (pink) or NL6-2 (dark cyan) respectively in the APH(3')-IIla-ADP.kanamycin A 625 complex. (E, F) Overlay of the best docking poses of NL6 and NL6-1 or NL6-2 respectively in 626 the apo structure of $\mathrm{APH}\left(3^{\prime}\right)$-IIla.

627

628 Fig. 6. (A, B) Crystal structures of the $\mathrm{APH}\left(3^{\prime}\right)$-IIla bound to $\mathrm{CKI}$-inhibitor (yellow sticks, PDB 629 ID: 3Q2J) or to AR_3A inhibitor (green cartoon, PDB ID: 2BKK), respectively. (C) Predicted 630 binding position of NL6 (grey sticks) in APH(3')-IIla. 


\section{Table 1.}

Docking scores and averaged in vitro APH inhibitions of selected NL compounds. Compounds that were not commercially available are indicated by an asterisk. Zinc numbers are indicated in brackets. Inhibitions of APH activity by $500 \mu \mathrm{M}$ of NL compound are expressed as percentage relative to the activity without compound. Inhibitions by $40 \%$ or more are highlighted in bold.

\begin{tabular}{|c|c|c|c|c|c|c|c|c|c|c|c|}
\hline & & \multicolumn{2}{|c|}{$\mathrm{APH}\left(3^{\prime}\right)-$ IIIa } & \multicolumn{2}{|c|}{ APH(2")-IVa } & \multirow[b]{2}{*}{$\begin{array}{l}\text { Compound } \\
\text { (ZINC number) }\end{array}$} & \multirow[b]{2}{*}{ Structure } & \multicolumn{2}{|c|}{ APH(3')-IIIa } & \multicolumn{2}{|c|}{ APH(2")-IVa } \\
\hline $\begin{array}{l}\text { Compound } \\
\text { (ZINC number) }\end{array}$ & Structure & Score & Inhibition & Score & Inhibition & & & Score & Inhibition & Score & Inhibition \\
\hline $\begin{array}{c}\text { NL1 } \\
(08981682)\end{array}$ & & 71 & 7 & 81 & 10 & $\begin{array}{c}\text { NL12 } \\
(40455179)\end{array}$ & & 75 & 0 & 66 & 17 \\
\hline $\begin{array}{c}\text { NL2 } \\
(20785546)\end{array}$ & & 73 & 0 & 80 & 26 & $\begin{array}{c}\text { NL13 } \\
(1792615)\end{array}$ & & 75 & 8 & 69 & 27 \\
\hline $\begin{array}{c}\text { NL3 } \\
(13001091)\end{array}$ & & 77 & 7 & 79 & 9 & $\begin{array}{c}\text { NL14 } \\
(6751595)\end{array}$ & & 61 & 0 & 68 & 0 \\
\hline $\begin{array}{c}\mathrm{NL}^{*} \\
(13001089)\end{array}$ & & 78 & nd & 78 & nd & $\begin{array}{c}\text { NL15* } \\
(36046879)\end{array}$ & & 76 & nd & 69 & nd \\
\hline $\begin{array}{c}\text { NL5 } \\
(22406103)\end{array}$ & & 80 & 20 & 77 & 19 & $\begin{array}{c}\text { NL16 } \\
(13572054)\end{array}$ & & 81 & 37 & 63 & 68 \\
\hline $\begin{array}{c}\text { NL6 } \\
(13236811)\end{array}$ & & 83 & 43 & 77 & 63 & $\begin{array}{c}\text { NL17 } \\
(14746000)\end{array}$ & & 80 & 0 & 63 & 12 \\
\hline $\begin{array}{c}\mathrm{NL7}^{*} \\
(52627502)\end{array}$ & & 80 & nd & 77 & nd & $\begin{array}{c}\text { NL18 } \\
(36589946)\end{array}$ & & 79 & 0 & 60 & 12 \\
\hline $\begin{array}{c}\text { NL8 } \\
(8790387)\end{array}$ & & 81 & 79 & 74 & 7 & $\begin{array}{c}\text { NL19 } \\
(8981627)\end{array}$ & & 75 & 3 & 63 & 0 \\
\hline $\begin{array}{c}\text { NL9 } \\
(1143187)\end{array}$ & & 80 & 12 & 71 & 45 & $\begin{array}{c}\text { NL20 } \\
(22357542)\end{array}$ & & 73 & 0 & 71 & 14 \\
\hline $\begin{array}{c}\text { NL10* } \\
(05277506)\end{array}$ & & 71 & nd & 68 & nd & $\begin{array}{c}\text { NL21 } \\
(12636347)\end{array}$ & & 64 & 37 & 63 & 24 \\
\hline $\begin{array}{c}\text { NL11 } \\
(20737652)\end{array}$ & & 67 & 2 & 64 & 14 & & & & & & \\
\hline
\end{tabular}


A

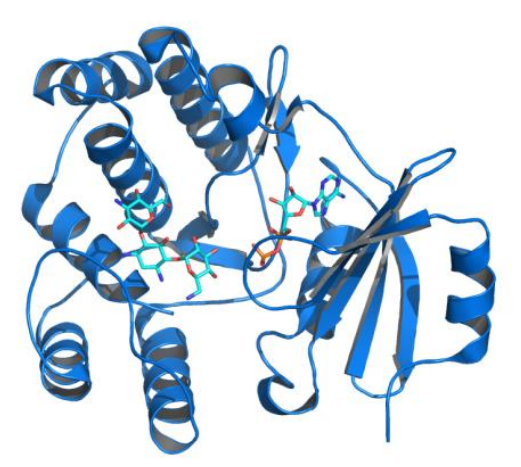

D

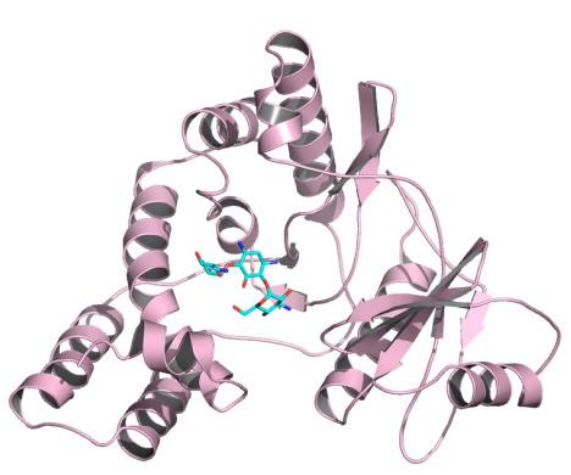

G

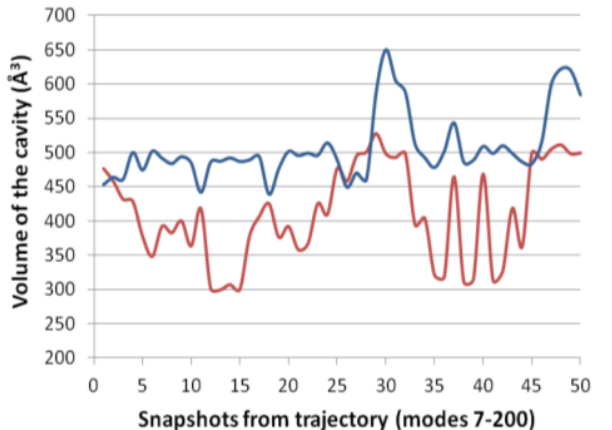

B

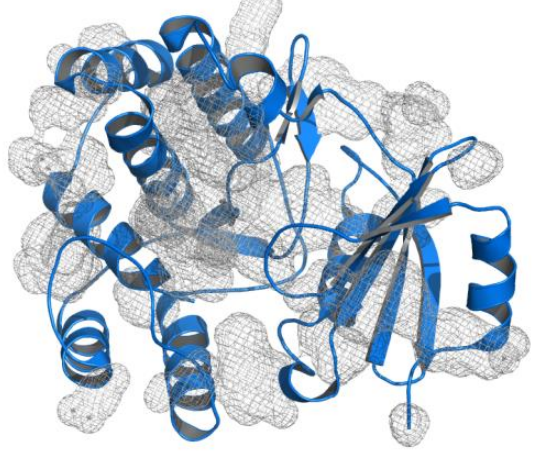

E

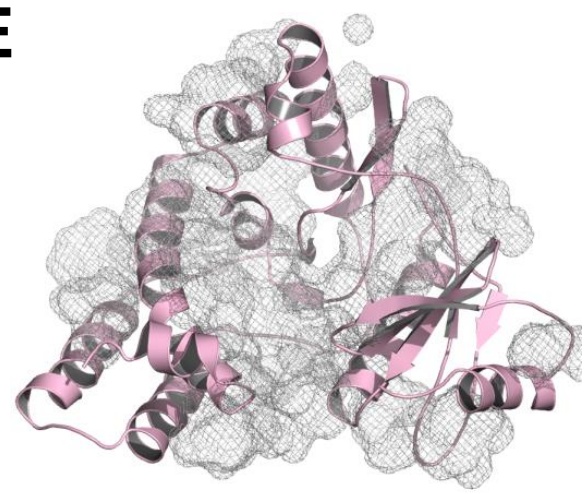

H

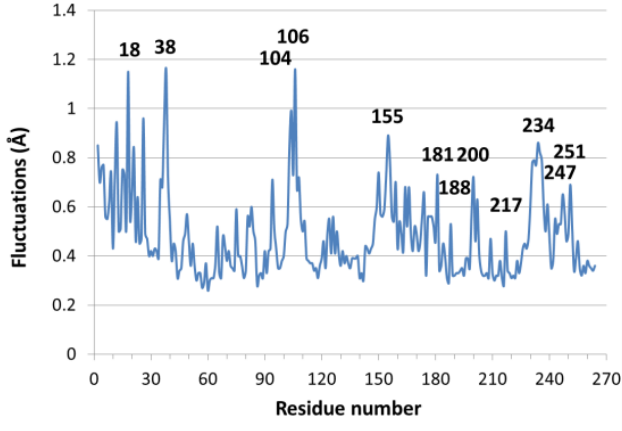

C

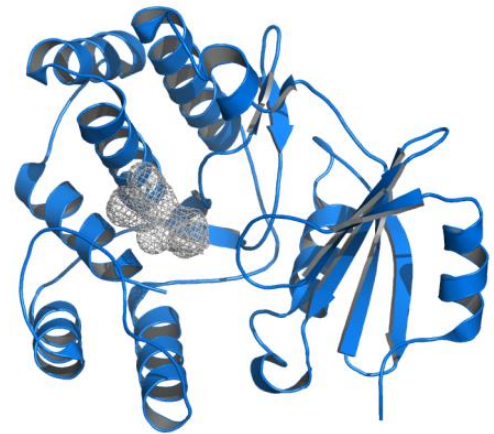

F

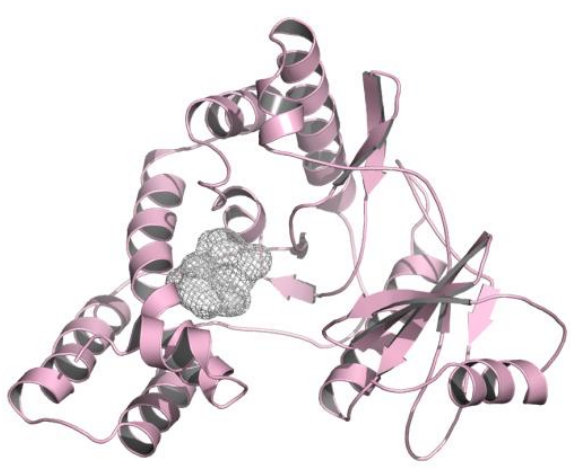

I

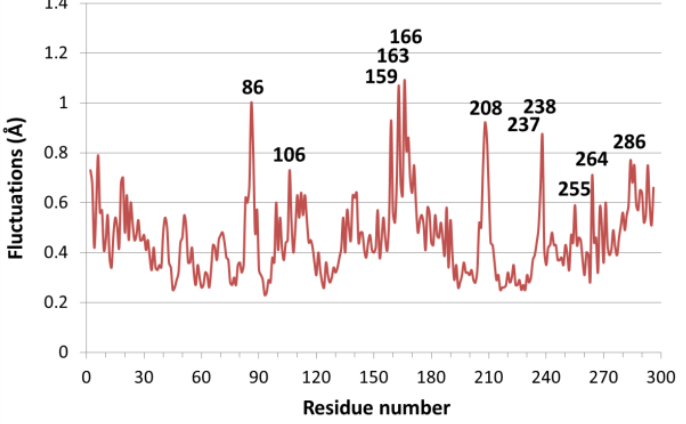



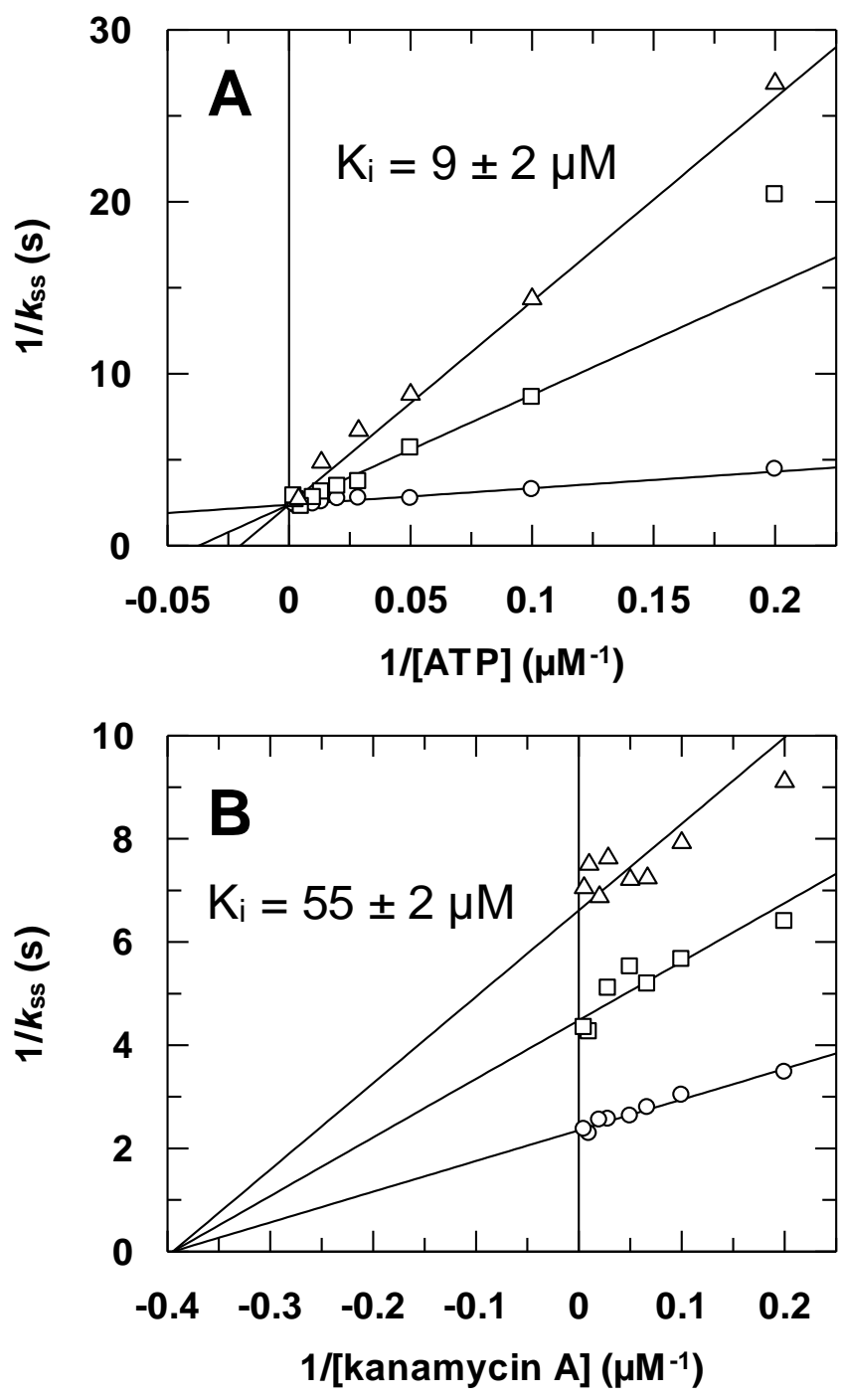

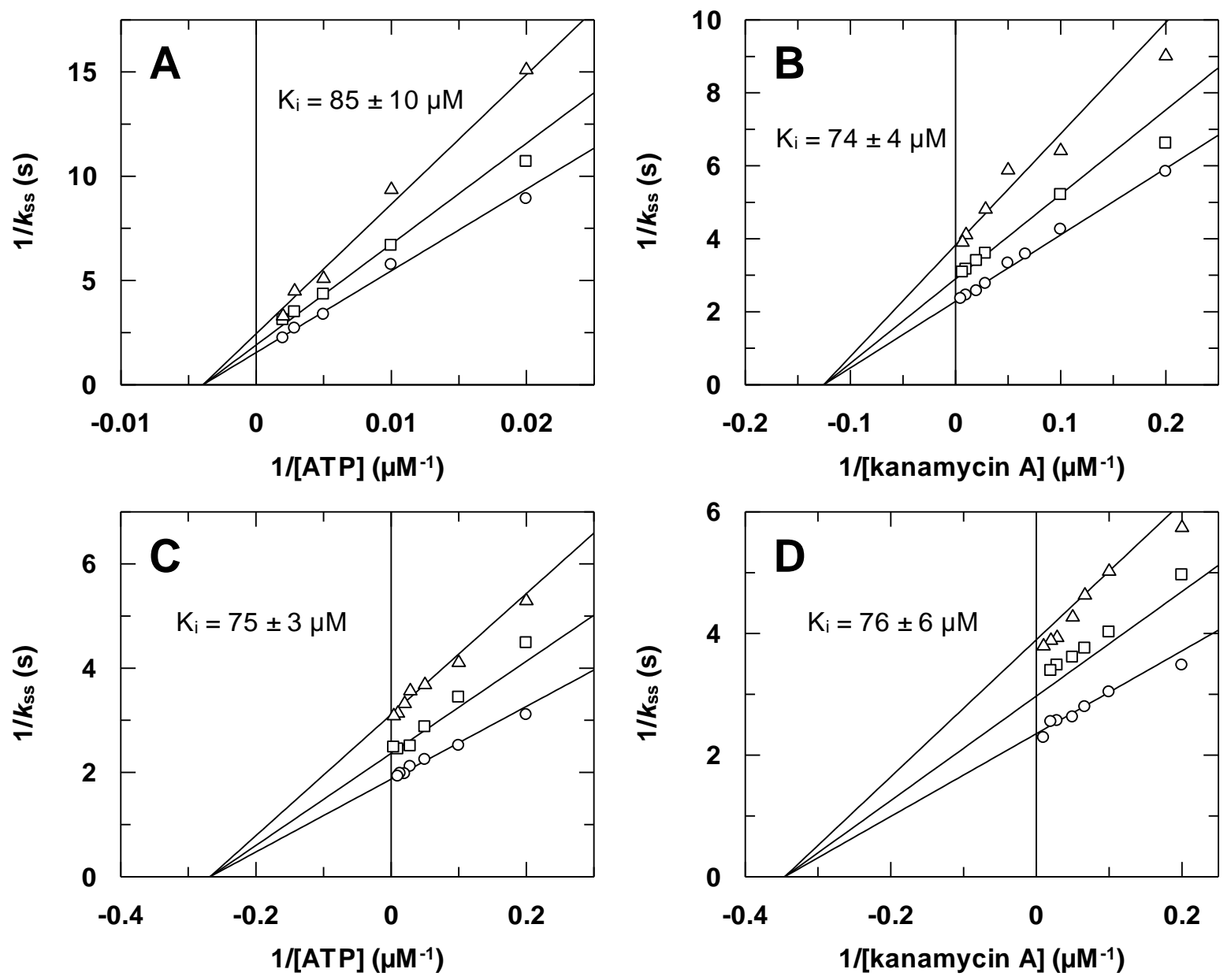

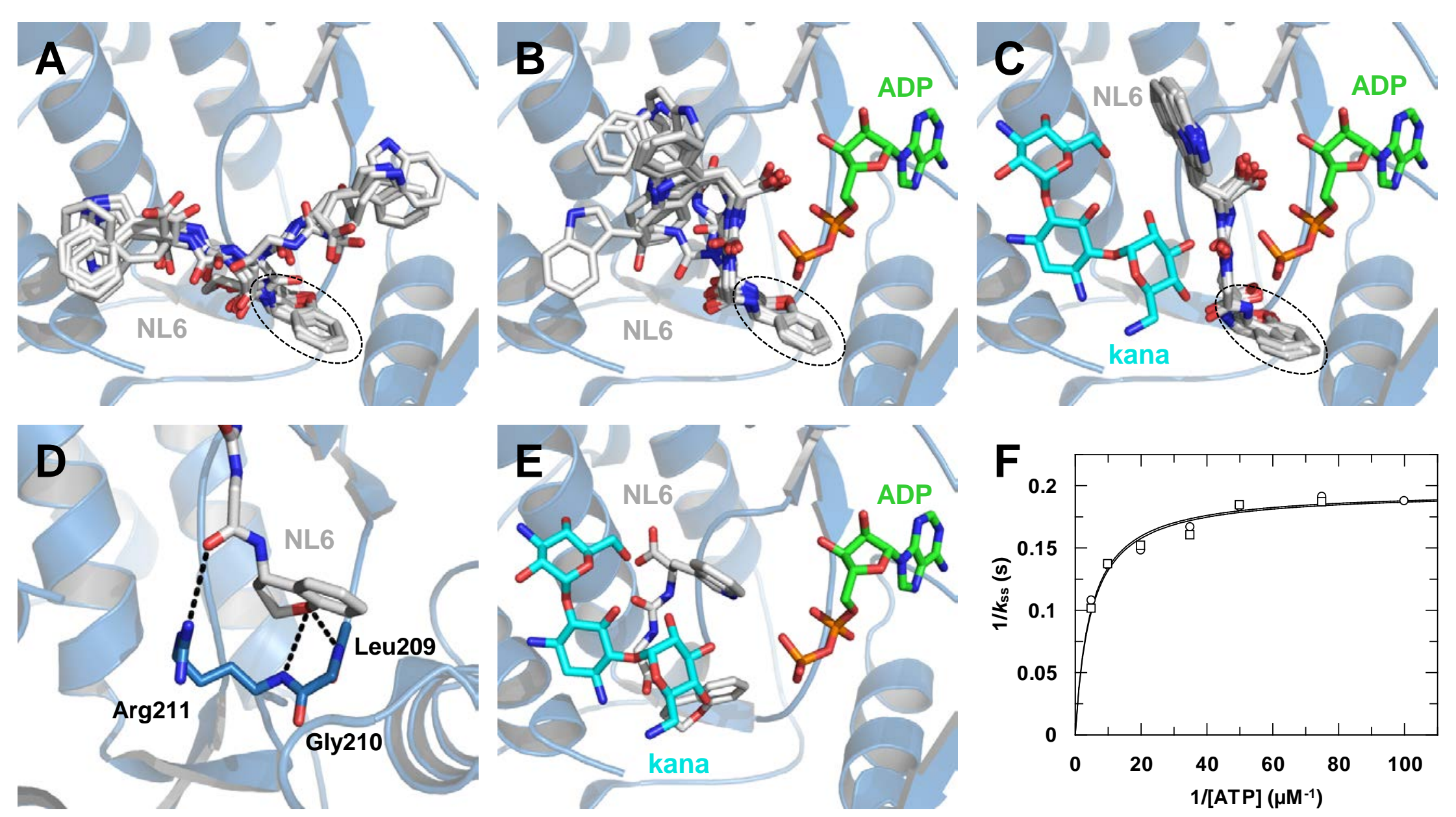
A

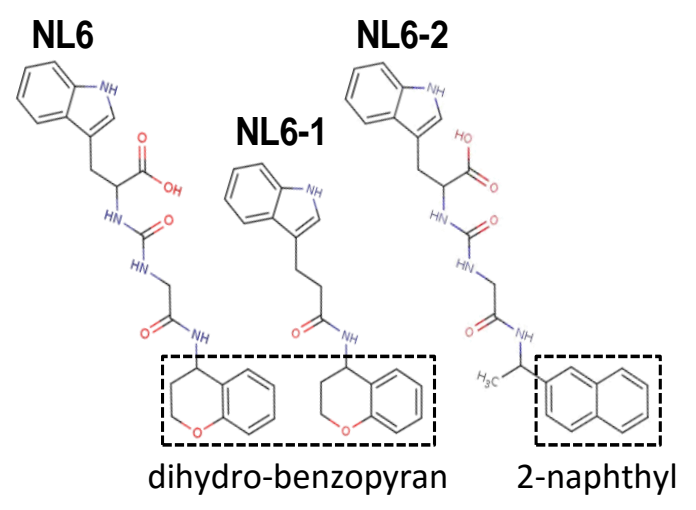

B
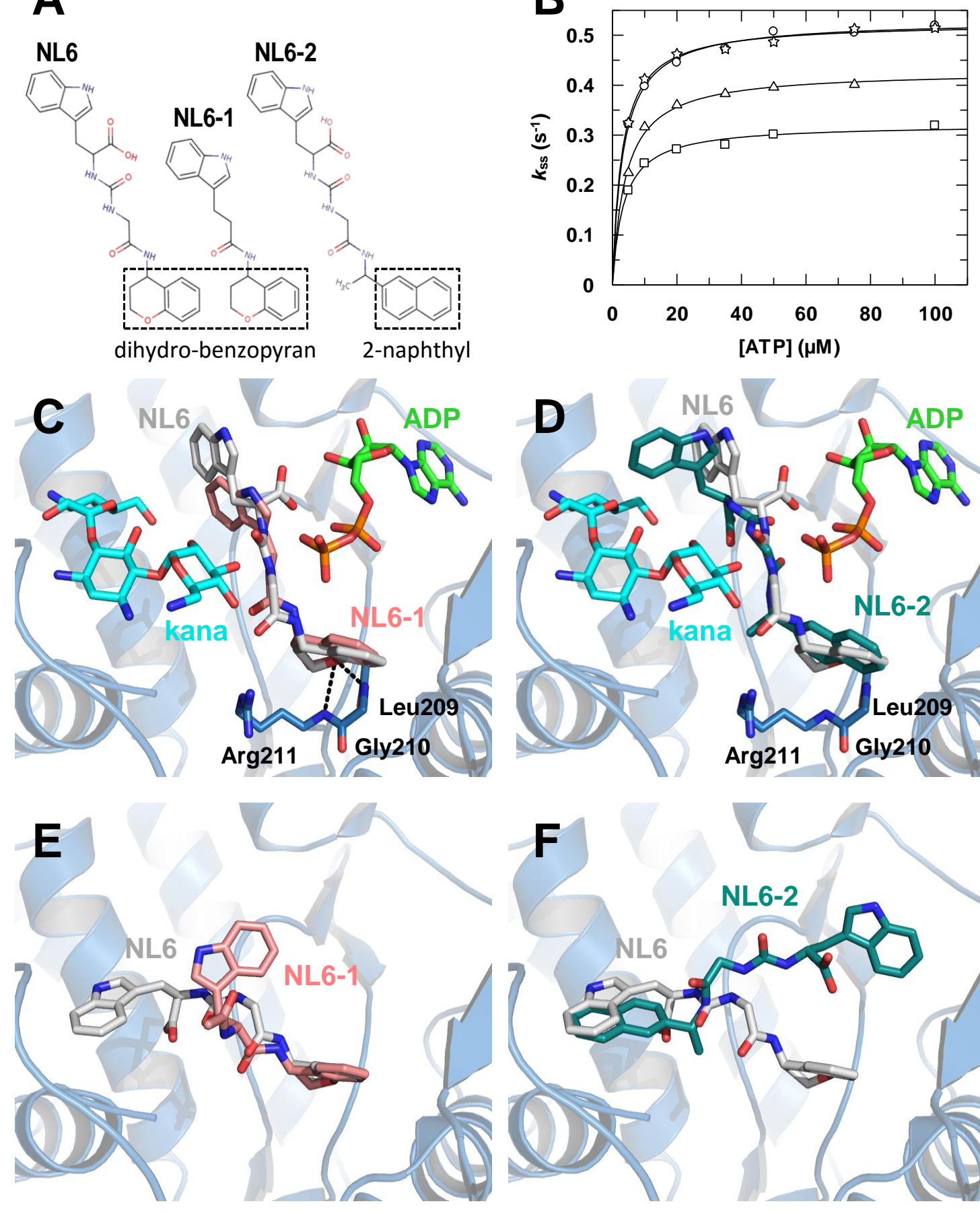
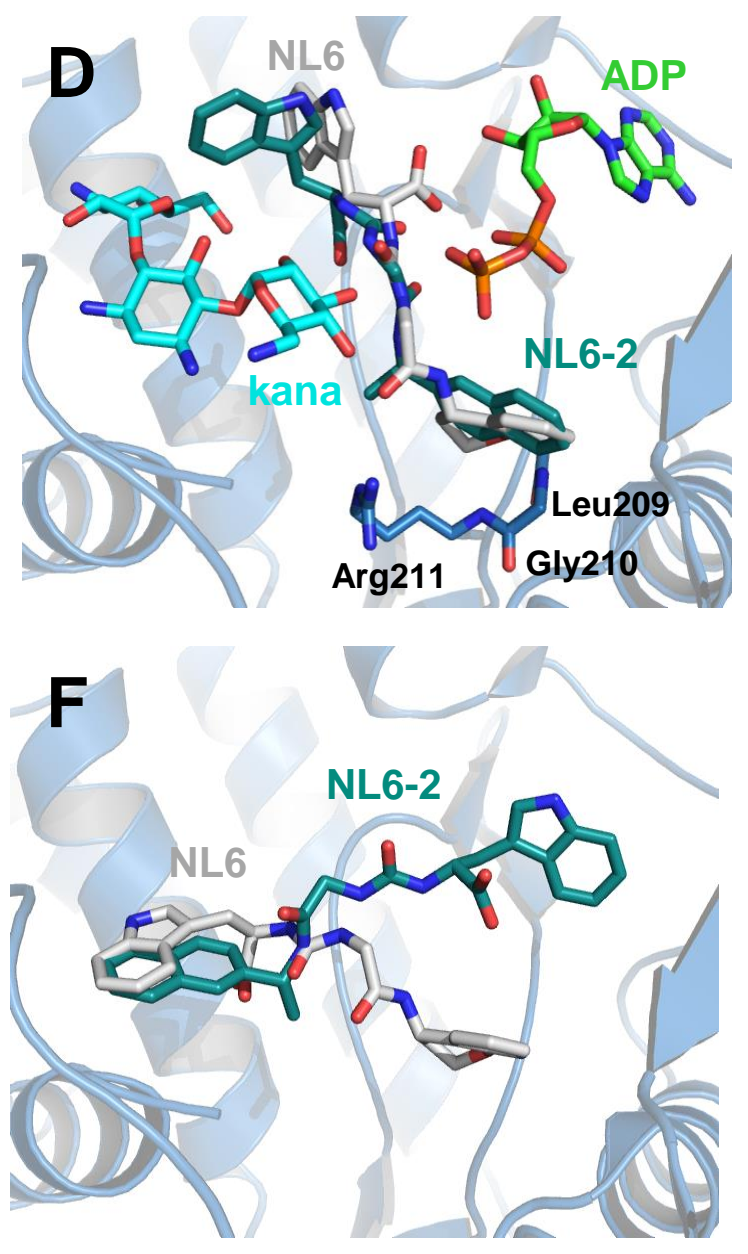

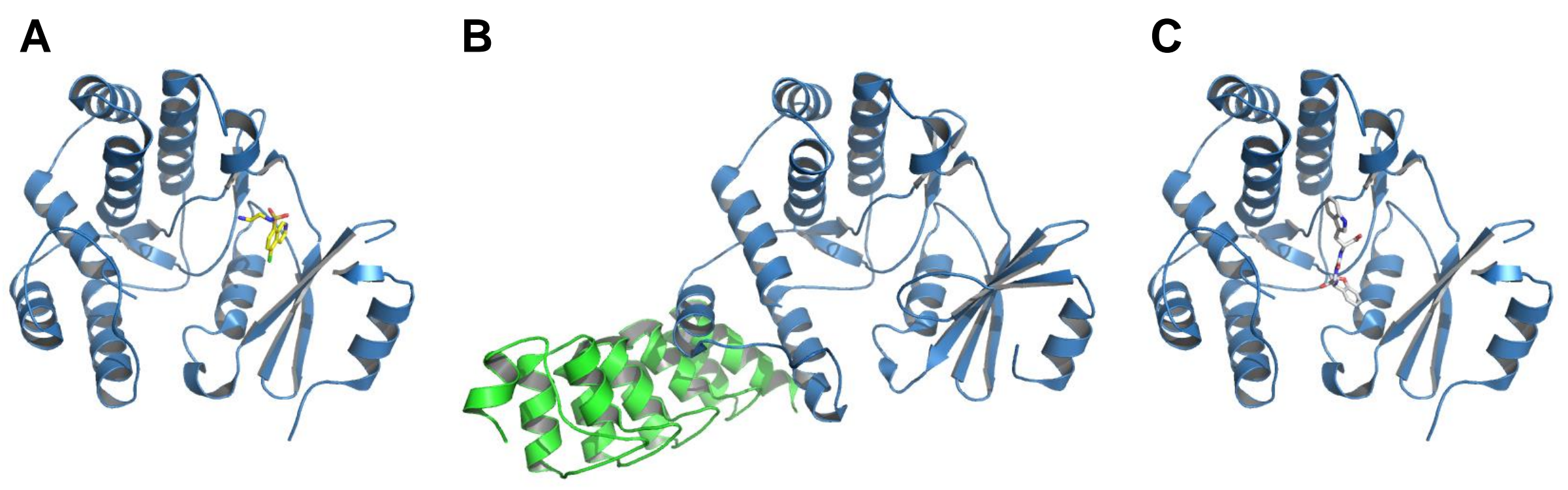


\section{WT}

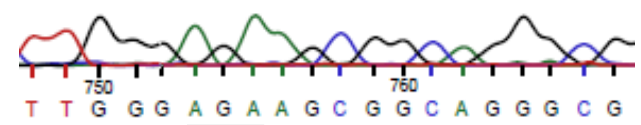

$\overline{\mathbf{R} 211}$

R211 A mutant

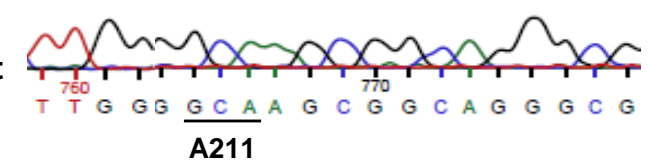

Fig. S1. Sequencing result showing the representative part of the aph(3')-IIla gene where the R211A mutation has been introduced. 

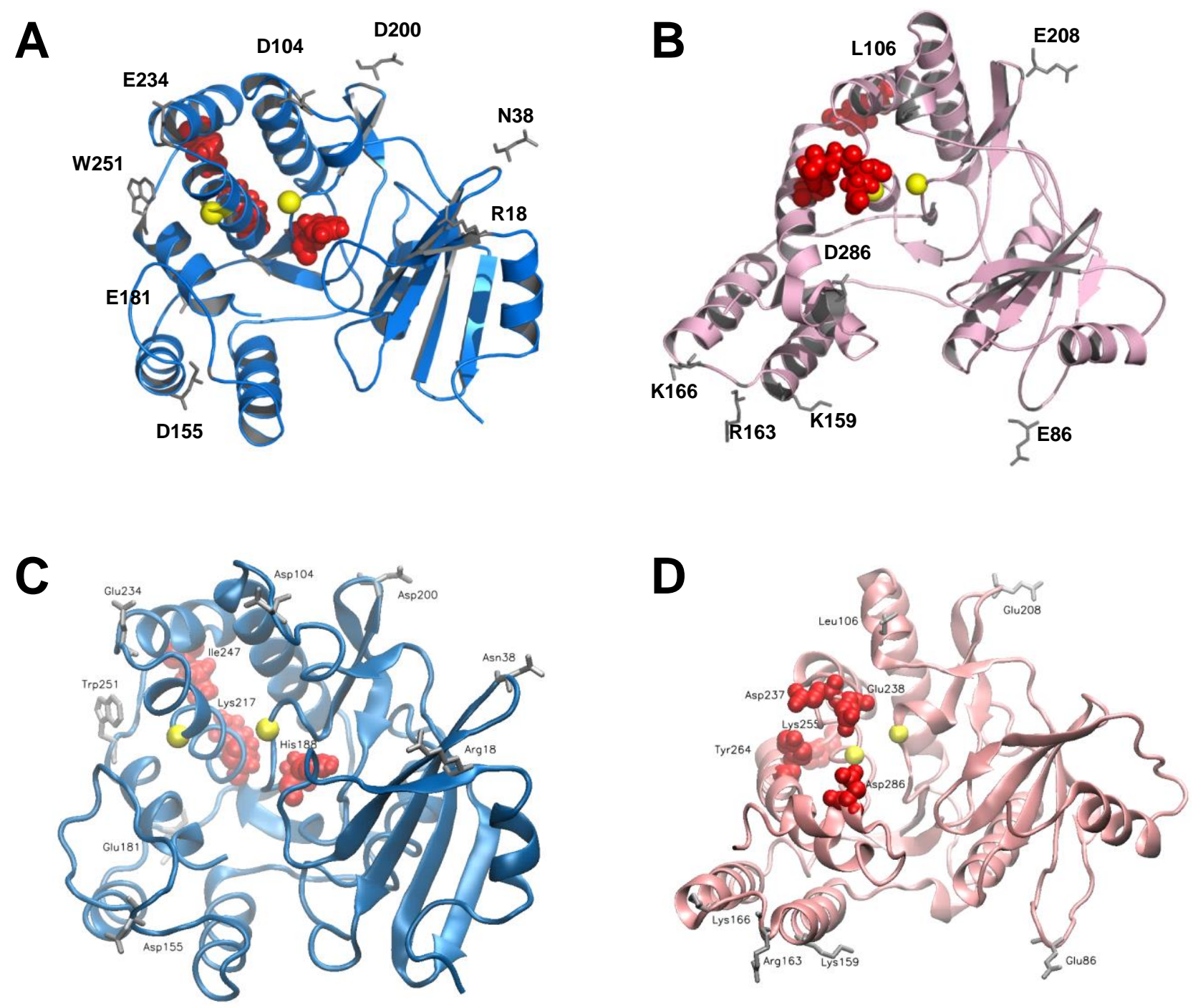

Fig. S2. Identification of the target cavities using normal mode analysis. (A, B) Crystal structures of APH(3')-IIla and APH(2")-IVa shown as blue or pink cartoon, respectively. The fluctuated residues involved in the cavity are shown as red balls: H188, K217 and I247 in APH(3')IIIa and D237, E238 and K255 in APH(2")-IVa. Yellow balls indicate CA atoms of the residues surrounding each cavity (G192 and R226 in APH(3')-IIla and S199 and S232 in APH(2")-IVa). (C, D) Movies showing the motions of APH(3')-IIla and APH(2")-IVa from superposed normal modes. Same representations as in A and B, respectively. 


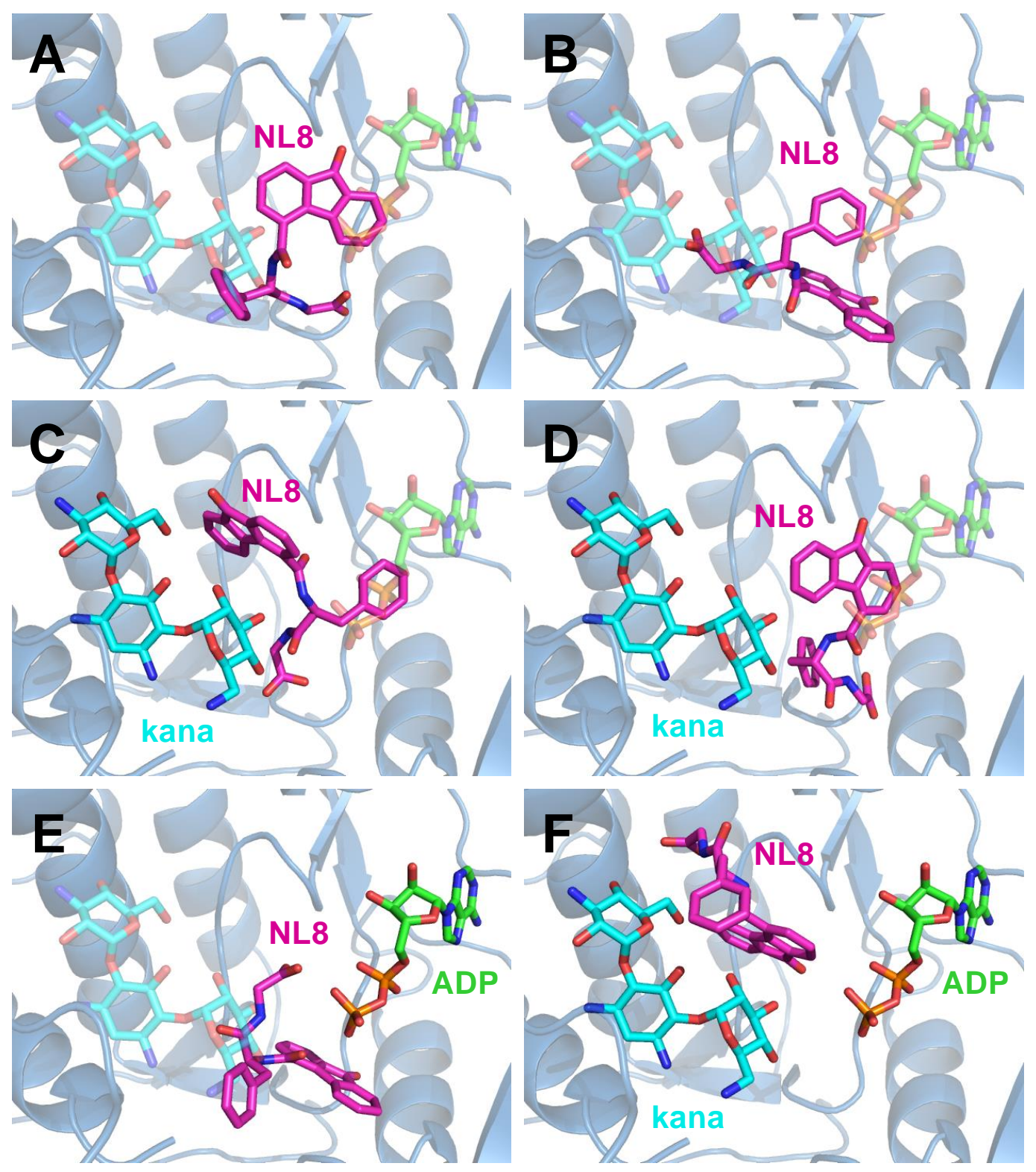

Fig. S3. Predicted binding poses obtained for NL8 by molecular docking using identical parameters either in the APH( $\left.3^{\prime}\right)$-IIla apo protein (A, B) or in the APH(3')-IIla-kanamycin A complex (C, D). Best docking poses of NL8 in the ADP-bound structure (E) or in the ternary complex (F). NL8 was docked into the 1L8T structure in which none, one or both ligands were conserved for docking. Removed ligands are shown in transparent sticks. 
Video Fig S2C
Click here to download Supplementary Multimedia File: Fig S2C.mpg Click here to download Supplementary Multimedia File: Fig S2C.mpg

$\sqrt{2}$

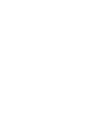

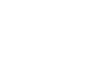

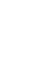

$\sqrt{3}$
(1) (1)

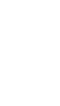
(1) .

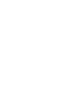
列

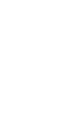

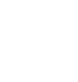

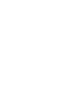

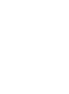

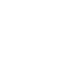

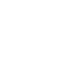

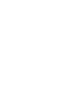

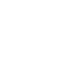

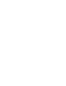

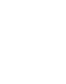

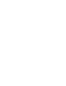

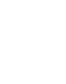

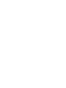

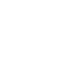

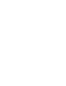
. (1) 
Video Fig S2D
Click here to download Supplementary Multimedia File: Fig S2D.mpg Click here to download Supplementary Multimedia File: Fig S2D.mpg

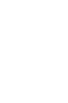

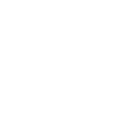

(1)

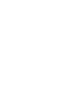

$\sqrt{2}$
(1)

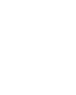
(1) (1)

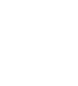

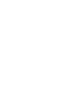
. .

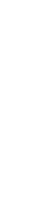
更

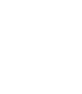
(

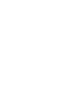

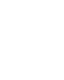

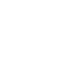

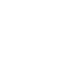

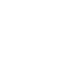

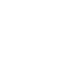
. .

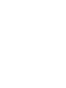
. .

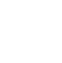

(1) 

Click here to download Supplementary Multimedia File: Supplementary material with video.pptx Supplementary Multimedia File
Click here to download Supplem click here to download Supplementary Multimedia File: Supplementary material with video.pptx 